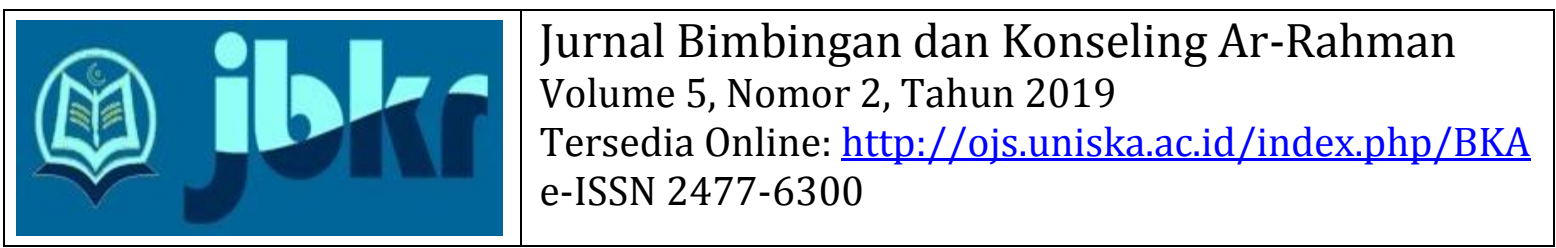

\title{
LAYANAN KONSELING KELOMPOK DENGAN TEKNIK POSITIVE REINFORCEMENT UNTUK MENINGKATKAN DISIPLIN SISWA DI SEKOLAH SMP NEGERI 9 BANJARBARU
}

\author{
Hasan, Farial, Nurmiati \\ Program Studi Bimbingan dan Konseling, Fakultas Keguruan dan Ilmu Pendidikan, Universitas Islam \\ Kalimantan Muhammad Arsyad Al-Banjari Banjarmasin \\ hbesar1996@gmail.com
}

\begin{abstract}
ABSTRAK
Disiplin adalah faktor yang sangat penting dimiliki seorang siswa dalam dunia pendidikan dan bekal untuk kehidupan selanjutnya bagi para siswa. Disiplin menunjuk pada kepatuhan seseorang dalam mengikuti peraturan atau tata tertib karena didorong oleh adanya kesadaran yang ada pada kata hatinya dan dikeluarkan oleh dirinya. Biasanya ketertiban terjadi lebih dahulu baru kemudian berkembang menjadi disiplin. Tata tertib adalah peraturan peraturan yang mengikat seseorang atau mengharuskan seseorang dan kelompok guna menciptakan keamanan. Tujuan penelitian ini adalah untuk meningkatkan disiplin siswa kelas VIII A SMP NEGERI 9 BANJARBARU dengan penguatan positif (Positive Reinforcement) dalam layanan konseling kelompok. Penelitan ini adalah penelitian eksperimen yaitu pre-eksperimental design one-group pretest dan posttest. Hasil penelitian menunjukan sebelum diberikan teknik positive reinforcement dalam penggunaan layanan konseling kelompok rata-rata skornya adalah 261,375 (70,5\%) dan sesudah diberikan teknik positive reinforcement dalam penggunaan layanan konseling kelompok maka diketahui hasilnya adalah sebanyak rata-rata 285,375 $(77,25 \%)$.
\end{abstract}

Kata Kunci: Konseling Kelompok; Teknik Positive Reinforcement; Disiplin

\section{ABSTRACT}

Discipline is a very important factor for students in the world of education and provision for the next life for students. Discipline refers to a person's approval in following rules or regulations because it is supported by the awareness that exists in the word peace and issued by faith. Usually order occurs first and then develops into discipline. Order is a regulation that binds a person or asks someone and a group to create security. The purpose of this study was to improve the discipline of students of class VIII A SMP NEGERI 9 BANJARBARU with positive reinforcement (Positive Strengthening) in group counseling services. This research is an experimental research that is pre-experimental one-group pretest and posttest design. The results showed before being given a positive reinforcement technique in the use of group counseling services the average score was $261,375(70.5 \%)$ and given a positive reinforcement technique in the use of group counseling services so as to produce an average of 285,375 (77.25\%).

Keywords: Group Counseling; Positive Reinforcement Techniques; Discipline 


\section{PENDAHULUAN}

Disekolah biasanya terdapat berbagai aturan dan tata disiplin yang harus di taati oleh seluruh siswanya, Untuk dapat menegakkan kesadaran hukum pada diri siswa, diperlukan adanya tata tertib dan peraturan-peraturan bagi para siswa yang diharapkan dengan adanya tata tertib, maka para siswa akan menaati peraturan yang berlaku sehingga akan terciptanya kedisiplinan tata tertib di sekolah. Menurut Suharsimi Arikunto (dalam Hidayat, 2013:95) ketertiban menunjukan pada kepatuhan seseorang dalam mengikuti peraturan atau tata tertib karena didorong atau disebabkan oleh sesuatu yang datang dari luar.

Disekolah biasanya terdapat berbagai aturan dan tata disiplin yang harus di taati oleh seluruh siswanya, Untuk dapat menegakkan kesadaran hukum pada diri siswa, diperlukan adanya tata tertib dan peraturan-peraturan bagi para siswa yang diharapkan dengan adanya tata tertib, maka para siswa akan menaati peraturan yang berlaku sehingga akan terciptanya kedisiplinan tata tertib di sekolah. Menurut Suharsimi Arikunto (dalam Hidayat, 2013:95) ketertiban menunjukan pada kepatuhan seseorang dalam mengikuti peraturan atau tata tertib karena didorong atau disebabkan oleh sesuatu yang datang dari luar.

Hal ini sejalan dengan pendapat Tu'u (2004:33) merumuskan bahwa disiplin adalah sebuah upaya untuk mengikuti dan menaati peraturan, nilai, dan hukum yang berlaku, yang muncul karena adanya kesadaran diri bahwa ketaatan itu berguna bagi kebaikan dan keberhasilan dirinya dan untuk dirinya dan juga menurut Paul Pigors \& Charles A. Myres (dalam Hidayat, 2013:95) bahwa disiplin itu mengacu pada ketertiban dan keteraturan yang berlaku. Kesadaran untuk menegakan peraturan itu merupakan dasar bagi para anggota kelompok dalam beraktivitas sesuai dengan peran masing-masing, tugas dan kewajiban masing-masing agar disiplin dapat dijamin dalam penerapan dan pelaksanaannya maka perlu diikuti oleh sanksi-sanksi kepada mereka yang melanggarnya, disiplin dalam dunia pendidikan penting halnya untuk seorang siswa, disiplin dalam menaati peraturan disekolah yang sudah diatur oleh sekolah dan akan selalu berlaku.

Penelitian ini menggunakan konseling kelompok yang mana konseling kelompok adalah menurut Dewa Ketut (dalam Marjanti, 2015) mengemukakan bahwa layanan konseling kelompok yaitu layanan bimbingan dan konseling yang memungkinkan peserta didik memperoleh kesempatan untuk pembahasan dan pengantasan permasalahan yang dialaminya melalui dinamika kelompok yang berjalan. Jadi tujuan konseling kelompok adalah berani berbicara didepan orang banyak dapat bertenggang rasa terhadap teman dan dapat mengembangkan minat masing-masing angota kelompok dan mengentaskan permasalahanpermasalahan yang ada didalam kelompok tersebut.

Kemudian layanan tersebut dibantu dengan teknik agar lebih maksimal penggunaannya teknik tersebut adalah berupa pemberian penguatan positif (positive reinforcement) yang menurut Komalasari (2014:161) penguatan positif (positive reinforcement) ialah peristiwa atau sesuatu yang akan membuat tingkah laku yang dikehendaki berpeluang diulang karena bersifat disenangi dan disukai. Dalam penerapannya teknik ini akan sangat diyakini yang mana suatu peristiwa yang dihadirkan atau dihadapkan dengan segera yang mengikuti perilaku menyebabkan perilaku tersebut menjadi meningkat frekwensinya. Kemudian penerapannya bisa berupa pujian dan dukungan kepada si penerima yang dikehendaki. jadi Positive Reinforcement adalah untuk membuat klien mendapatkan apresiasi yang sangat tinggi dari si pemberi perlakuan dan bertujuan untuk meningkatkan frekwensi tingkah lakunya yang positif tentunya.

\section{METODE}

Dalam penelitian ini menggunakan Pre-eksperimental design, yaitu one-group pretest dan posttest, pretest adalah sebelum siswa diberikan perlakuan kemudian sesudah diberi perlakuan atau posttest, populasi siswa dalam penelitian ini adalah siswa kelas VIII A SMP NEGERI 9 BANJARBARU. Berdasrkan hasil skor angket skala kedisiplinan diambil sampel 8 orang siswa dari 27 populasi dengan menggunakan angket skala kedisiplinan yang mana skor terendah akan diberikan perlakuan layanan konseling kelompok dengan teknik positive reinforcement. Analisis kuantitatif menggunakan statistik uji wilcoxon untuk menguji perbandingan konseling kelompok yang bisa digunakan pada siswa kelas VIII A SMP NEGERI 9 BANJARBARU. Analisis data merupakan kegiatan setelah data dari seluruh responden atau sumber data lain terkumpul. Setelah itu akan dibandingkan keadaan sebelum dan sesudah diberi perlakuan dan akan di uji dengan teknik analisis data dengan rumus wilcoxon.

\section{HASIL DAN PEMBAHASAN}

Berdasarkan hasil penelitian tingkat disiplin siswa kelas VIII A SMP NEGERI 9 BANJARBARU sebelum diberikan teknik positive reinforcement dalam penggunaan layanan konseling kelompok ratarata $261,375(70,5 \%)$ dan sesudah diberikan teknik positive reinforcement dalam penggunaan layanan konseling kelompok maka diketahui hasilnya adalah sebanyak rata-rata $285,375(77,25 \%)$. 
Hasan, Farial, Nurmiati

Jurnal Bimbingan dan Konseling Ar-Rahman

Volume 5, Nomor 2, Tahun 2019

e-ISSN 2477-6300

Tabel 1. Hasil pretest dan posttest

\begin{tabular}{ccccccccc}
\hline $\begin{array}{c}\text { Respond } \\
\text { en }\end{array}$ & \multicolumn{3}{c}{ Pre-test } & \multicolumn{3}{c}{ Post-test } & \multicolumn{3}{c}{$\begin{array}{c}\text { Peningkata } \\
\text { n Skor }\end{array}$} \\
& Skor & \% & K & Skor & $\%$ & K & & $\%$ \\
\hline R-1 & 264 & 71 & T & 283 & 76 & T & +19 & 5 \\
R-2 & 259 & 70 & T & 271 & 73 & T & +12 & 3 \\
R-3 & 279 & 75 & T & 324 & 88 & ST & +45 & 12 \\
R-4 & 256 & 69 & T & 280 & 76 & T & +24 & 6 \\
R-5 & 265 & 72 & T & 296 & 80 & T & +31 & 8 \\
R-6 & 276 & 75 & T & 306 & 83 & T & +30 & 8 \\
R-7 & 246 & 66 & S & 254 & 69 & T & +8 & 2 \\
R-8 & 246 & 66 & S & 269 & 73 & T & +23 & 6 \\
Rata- & 261, & 70,5 & T & 285,37 & 77,2 & T & +24 & 6,25 \\
rata & 375 & & & 5 & 5 & & &
\end{tabular}

Untuk membuktikan hipotesis yang diajukan pada penelitian ini yaitu Layanan konseling kelompok dengan teknik positive reinforcement maka diadakan uji dengan analisis wilcoxon berikut :

Tabel 2. Hasil Analisis Wilcoxon

\begin{tabular}{cccccc}
\hline Data & $\mathrm{Z}$ & $\begin{array}{c}\text { Asymp. } \\
\text { Sig }\end{array}$ & $<0,05$ & $>0,05$ & $\begin{array}{c}\text { Ketera } \\
\text { ngan }\end{array}$ \\
\hline Prete & - & 0,012 & Diteri & Tidak & Diteri \\
st- & 2.25 & & ma & diteri & ma \\
Postt & $1^{\mathrm{b}}$ & & & ma & \\
est & & & & & \\
\hline
\end{tabular}

Berdasarkan tabel 4.6 diatas dapat dilihat bahwa data Pre-test dan Post-test hasil analisis menggunakan wilcoxon pada aplikasi SPSS menunjukan nilai Asymp.Sig sebesar 0,012 dengan demikian hasil analisis tersebut diterima karena dasar pengambilan keputusan wilcoxon adalah $<0,05$ yang berarti (Ho) ditolak dan (Ha) diterima karena adanya pengaruh disiplin siswa disekolah sebelum dan sesudah diberikan layanan Konseling Kelompok dengan Teknik Positive Reinforcement

Berdasarkan penjelasan hasil penelitian pada pre-test sebelum diberikan teknik positive reinforcement dalam penggunaan layanan konseling kelompok untuk meningkatkan disiplin siswa, tidak ditemukan siswa yang memiliki kategori skor (Rendah), (Sangat Rendah), dan (Sangat Tinggi). Adapun kategori skor interval pada pre-test dan posttest Terdapat 6 orang siswa yang memiliki kategori skor Tinggi dan 2 orang siswa dengan ketegori skor Sedang, Setelah post-test berubah menjadi 7 orang yang memiliki skor Tinggi dan satu orang menjadi skor Sangat Tinggi.

Adapun rata-rata hasil yang diperoleh pada post-test sebanyak 261,375 (70,5\%). Dan setelah pretest atau sesudah perlakuan diperoleh hasil rata-rata skor 285,375 (77,25\%). Dengan demikian penggunaan
Layanan konseling kelompok dengan teknik positive reinforcement dapat meningkatkan kedisiplinan siswa kelas VIII A SMP NEGERI 9 BANJARBARU.

Berdasarkan pada hasil penelitian teknik positive reinforcement dalam penggunaan layanan konseling kelompok untuk meningkatkan disiplin siswa pada SMP NEGERI 9 BANJARBARU Setelah dilakukan pengujian dengan rumus Wilcoxon terbukti bahwa Layanan konseling kelompok dengan teknik positive reinforcement dapat meningkatkan tingkat disiplin siswa. Hal ini lebih memperkuat dari penelitian sebelumnya teknik positive reinforcement terbukti efektif dalam meningkatkan kedisiplinan siswa dengan layanan konseling kelompok

\section{PENUTUP}

Berdasarkan pada hasil penelitian teknik positive reinforcement dalam penggunaan layanan konseling kelompok untuk meningkatkan disiplin siswa pada SMP NEGERI 9 BANJARBARU sebagai berikut : (1) Tingkat disiplin siswa sebelum diberikan teknik positive reinforcement dalam penggunaan layanan konseling kelompok rata-rata 261,375 $(70,5 \%)$. dengan kategori Tinggi. (2) Tingkat disiplin siswa sesudah diberikan teknik positive reinforcement dalam penggunaan layanan konseling kelompok rata-rata 285,375 (77,25\%) dengan kategori Tinggi. (3) Perubahan sebelum dan sesudah diberikan teknik positive reinforcement dalam penggunaan layanan konseling kelompok mengalami peningkatan rata-rata sebanyak skor $24(6,25 \%)$ (4) Dua orang siswa yang memiliki skor terendah dengan kategori Sedang setelah post-test mengalami kenaikan skor dengan kategori Tinggi dan satu orang siswa yang semula mempunyai skor dengan kategori Tinggi pun mengalami peningkatan skor menjadi kategori Sangat Tinggi. (5) Setelah dilakukan pengujian dengan rumus Wilcoxon terbukti bahwa Layanan konseling kelompok dengan teknik positive 
reinforcement dapat meningkatkan kedisiplinan siswa di sekolah SMP NEGERI 9 BANJARBARU.

Berdasarkan hasil penelitian diketahui bahwa kedisiplinan siswa pada kelas VIII A SMP NEGERI 9 BANJARBARU, berkenaan dengan hal tersebut peneliti dapat memberikan saran : (1) Kepada Guru bimbingan dan konseling agar menerapkan layanan konseling kelompok dengan Teknik Positive Reinforcement agar harapannya kedisiplinan siswa lebih membaik. (2) Siswa lebih menerapkan akan pentingnya disiplin disekolah dan diluar sekolah karena disiplin adalah kunci utama dalam kesuksesan. (3)Peneliti selanjutnya agar menggunakan Layanan Konseling kelompok dan Teknik Positive Reinforcement ini untuk penggunaan yang optimal dan mencari teori dengan jumlah indikator angket yang lebih dari penelitian skala kedisiplinan ini agar penelitian konseling kelompoknya nanti lebih dari 3 pertemuan, sehingga hasil yang di capai akan lebih optimal dalam penerapannya.

\section{REFERENSI}

Komalasari, G., \& Wahyuni, E., Karsih. (2014). Teori dan Teknik Konseling (Revised Ed). Jakarta: Indeks.

Hidayat, H. S. (2013). Pengaruh Kerjasama Orang Tua dan Guru Terhadap Disiplin Peserta Didik Di Sekolah Menengah Pertama (SMP) Negeri Kecamatan Jagakarsa-Jakarta Selatan. Jurnal Ilmiah WIDYA, 1(2), $92-$ 99.

Lubis, N.L., \& Hasnida. (2016). Konseling Kelompok. Jakarta: Prenada Media

Marjanti, S. (2015). Upaya Meningkatkan Rasa Percaya Diri Melalui Konseling Kelompok Bagi Siswa X IPS 6 SMA 2 BAE KUDUS Tahun Pelajaran 2014/2015. Jurnal Konseling GUSJIGANG, 1 (2).

Sugiyono. (2015). Prosedur Penelitian Pendidikan. Bandung: Afabeta.

Tu'u, T. (2004). Peran Disiplin pada Perilaku dan Prestasi Siswa. Jakarta: Grasindo. 